\title{
FUNGI IN FLUIDS-A HAZARD OF INTRAVENOUS THERAPY
}

\author{
M. H. ROBERTSON \\ St Margaret's Hospital, Epping, Essex
}

INTRAVENOUS fluids have become an indispensable part of modern therapy and large quantities of commercially and locally manufactured fluids are used in treatment daily. Their production is strictly controlled to ensure that they are free from bacteria, that their chemical composition is accurate and that they are free from pyrogens and particulate matter. The rarity of accidents due to the use of intravenous fluids is proof of the adequacy of these controls, but there is reason to fear that procedures designed to detect particulate matter, which may include fungus spores, have been inadequate (Garvan and Gunner, 1963, 1964). Mishaps do occur, however, due to human error at the bedside. The object of this communication is to draw attention to one such hazard and to describe a course of action successfully taken on two occasions when it arose.

\section{OBSERVATIONS}

\section{Case 1}

A 26-yr-old primigravida, delivered of a healthy infant, suffered a postpartum haemorrhage of two pints $(1100 \mathrm{ml})$ and an intravenous infusion of glucose-saline was given. After approximately $200 \mathrm{ml}$ of fluid had been administered it was noticed that the bottle was cracked and that the fluid contained clumps of green fungus, subsequently identified as a Trichoderma sp. The drip was immediately stopped and she was admitted to this hospital for observation and treatment. On arrival her general condition gave no cause for alarm. Examination showed her temperature to be $36 \cdot 1^{\circ} \mathrm{C}\left(97^{\circ} \mathrm{F}\right)$, pulse rate 140 per min., B.P. 140/100. Her chest and heart sounds were normal and no abnormality was found on examination of the abdomen. A blood culture was taken, which grew a Trichoderma sp. after 3 days at room temperature; her white blood count at this time was 26,000 per $\mu 1,96$ per cent. being polymorphs.

It was decided to treat her initially for $24 \mathrm{hr}$ with amphotericin B (Fungizone) at a dosage of $0.25 \mathrm{mg}$ per $\mathrm{kg}$ body weight per day, given by slow intravenous drip in 5 per cent. dextrose solution. She was also treated with ampicillin $250 \mathrm{mg}$ 6-hourly in case of concomitant bacterial infection. Next day her temperature was $37.7^{\circ} \mathrm{C}\left(100^{\circ} \mathrm{F}\right)$ and she complained of feeling feverish, and of headache and generalised aches and pains. Physical examination revealed nothing of note and the administration of the drug was stopped, but ampicillin therapy was continued for a further week. Twenty-four hours later

Received 17 May 1969; accepted 3 July 1969.

J. MED. MICROBIOL.-vol. 3 (1970) 
she was afebrile and felt much better; her white blood count was 7600 per $\mu \mathrm{l}$, 68 per cent. being polymorphs; her blood urea was $24 \mathrm{mg}$ per $100 \mathrm{ml}$; and her liver function tests were normal apart from a slightly raised SGOT of 35 units. Her serum bilirubin was $0.3 \mathrm{mg}$ per $100 \mathrm{ml}$, alkaline phosphatase $16.8 \mathrm{~K}$.A. units, thymol turbidity 3 units and zinc turbidity (Kunkel) 3 units.

A second blood culture taken the day after the administration of amphotericin B remained sterile. She was discharged home and has remained well.

\section{Case 2}

A 39-yr-old woman was admitted for fusion of the lumbosacral spine. She had suffered from low backache for $15 \mathrm{yr}$. In the recovery room the anaesthetist noticed that the bottle of glucose-saline set up as an intravenous drip in the theatre was cracked and contained a few small white clumps. This was subsequently shown to be a Penicillium sp. The drip was immediately discontinued, but approximately $100 \mathrm{ml}$ of fluid had already been administered. This patient was also treated with amphotericin B. The same dosage, $0.25 \mathrm{mg}$ per $\mathrm{kg}$ per day, and the same means of administration were used. No other antibiotics were given. A blood culture taken before therapy commenced failed to grow the fungus.

Next day the patient felt well apart from an ache in the legs; her temperature was $37.5^{\circ} \mathrm{C}\left(99.6^{\circ} \mathrm{F}\right)$ and her blood urea level $40 \mathrm{mg}$ per $100 \mathrm{ml}$. Subsequent convalescence was uneventful and she has remained well.

\section{TECHNICAL PROCEDURES}

In both cases the fungus was identified by slide culture (Riddell, 1951). In the first case typical globular clusters of single-celled conidia were seen at the ends of short conidiophores identifying the fungus as a Trichoderma sp., and in the second case the typical " brush heads" made identification as a Penicillium sp. obvious. Both fungi were shown to be sensitive to amphotericin B by the disk diffusion method, in which disks containing $20 \mu \mathrm{g}$ of the drug were placed on inoculated blood agar plates, which were then incubated at room temperature until good growth was obtained ( 7 days in the first case, 3 days in the second). The zone of inhibition round the disk was $37 \mathrm{~mm}$ in diameter with the Trichoderma species and $25 \mathrm{~mm}$ in diameter with the Penicillium species.

\section{DISCUSSION}

Bottles of infusion fluid may become contaminated by fungi. Such fungi are usually regarded as non-pathogenic, but experimental work on rabbits has shown that intravenous infusion of spore suspensions of Rhizopus and Aspergillus spp. produces widespread lesions, and a heavy infusion can be fatal in a few days in that animal (Chick, Evans and Baker, 1958; Evans and Baker, 1959). The animals can be protected by intravenous administration of amphotericin B if treatment is commenced within a few hours of infection. Aspergillus spp. are also pathogenic for mice when injected intravenously, producing lesions in the central nervous system (Pore and Larsh, 1968). Intravenous infection with Candida species in man is well documented in drug addicts (Joachim and Polayes, 1940; Wikler et al., 1942) and the possibility of infection from bottles of intravenous glucose solution given as treatment has been discussed (Geiger 
et al., 1946; Duhig and Mead, 1951), but not proven. Disseminated candida infections are usually fatal. Whether the two patients described above were in grave danger is conjectural, but they may well have been so. It was decided to administer a toxic but effective drug without delay, since delay would render the treatment ineffective. In neither case did the patient come to any harm after 24 hours' treatment with amphotericin B, and neither patient showed any evidence of a generalised fungal infection thereafter.

It is easy to see how cracked infusion bottles can become infected with spores. Cracks may result from faulty or careless handling of the bottles. Cracking may also occur in the autoclave and is a recognised hazard. Rigid inspection of the bottles when they leave the autoclave is necessary.

Fungi may also contaminate intact bottles of fluid. The colony of fungus is usually found growing on the underside of the rubber stopper and may be very difficult to see on cursory inspection. It may be dislodged, however, when the needle of a giving set is inserted and thus becomes obvious. In this event the fluid is not administered.

How intact bottles become contaminated is not clear. Abnormally heatresistant spores may be present initially in the fluid and survive an inadequate sterilisation process, or such spores are liberated into the fluid from the rubber stopper (Garvan and Gunner, 1963, 1964). Another possibility is that organisms have been sucked into the bottle through a minute self-sealing fault in the closure during the cooling stage of the autoclave cycle. This is the mechanism postulated for the contamination of tins of corned beef with typhoid bacilli during processing in the factory (Ash et al., 1964). The mechanism involved is well discussed by Howie (1968).

The possibility of contamination from the stopper is worthy of further comment. Garvan and Gunner $(1963,1964)$ have shown that a wide variety of potentially harmful particles are showered into fluids by rupture of gas bubbles in the rubber stoppers during sterilisation. These particles include spores of Montospora and Alternaria spp. probably present in the raw rubber. Forty per cent. of particle-containing fluids in their study contained fungal elements and culture of one particular batch of 5 per cent. dextrose solution, which was heavily contaminated, produced growth of Montospora sp. in 1 out of 7 cultures from an inoculum of $5 \mathrm{ml}$. They point out that the viability of the scanty fungal elements present in most fluids could be determined only by culture of $500-\mathrm{ml}$ samples. It is of interest to note that these authors also state that spores could be liberated from rubber closures in the cold a month after sterilisation owing to expansion of bubbles produced by the vacuum inside the bottle, the bung becoming more friable as it ages. They could also be introduced into the fluid when the stopper is penetrated by the needle of a giving set, but as they would have no time to multiply before being administered to the patient the small amount of contamination introduced in this way is probably of little account.

Bottles used for intravenous administration should be examined very carefully for cracks and fungus growth on the bung before the contents are administered to patients. 


\section{SUMMARY}

Fluid contaminated with fungi was inadvertently administered intravenously to two patients. In both instances the bottle was cracked. However, apparently intact bottles can also show visible signs of growth. Both patients were treated with amphotericin B in a dose of $0 \cdot 25 \mathrm{mg}$ per $\mathrm{kg}$ body weight for $24 \mathrm{hr}$ without toxic effects. There was complete recovery. It is suggested that all bottles used for intravenous therapy should be carefully inspected before use.

It is a pleasure to thank the clinicians involved in the treatment of these cases for access to clinical information and encouragement to publish. Thanks are also due to Mr G. Hoy for technical assistance.

\section{REFERENCES}

Ash, I., McKendrick, G. D. W., Rob- 1964. Br. Med.J., 1, 1474. ERTSON, M. H., AND Hughes, H. L.

Chick, E. W., Evans, J., ANd Baker, 1958. Antibiotics Chemother., 8, 394.

R. D.

Duhig, J. V., ANd Mead, Margaret . 1951. Med. J. Austral., 1, 179.

EVANS, J. M., AND BAKER, R. D. . . 1959. Antibiotics Chemother., 9, 209.

Garvan, J. M., ANd Gunner, B. W. . 1963. Med. J. Austral., 2, 140.

" " $\quad$ " . 1964. Ibid., 2, 1.

Geiger, A. J., Wenner, H. A., Axilrod, 1946. Yale J. Biol. Med., 18, 250.

H. D., AND DURLACHER, S. H.

HowIE, J. W. . . . . $\quad$. . 1968. J. Appl. Bact., 31, 171.

Joachim, H., and Polayes, S. H. . $\quad$. 1940. J. Amer. Med. Assoc., 115, 205.

PoRE, R. S., AND LaRSH, H. W. . $\quad$ - 1968. Sabouraudia, 6, 89.

RIDDELL, R. W. . . . . . 1951. In Recent advances in clinical pathology, 2nd ed., edited by S. C. Dyke, London, p. 98.

Wikler, A., Williams, E. G., Douglass, 1942. J. Amer. Med. Assoc., 119, 333.

E. D., EMmons, C. W., AND DunN,

R. C. 